\title{
TIPOS DE TEMPO E RITMO PLUVIAL NA REGIÃO METROPOLITANA DE SÃO PAULO (RMSP): ANÁLISE COMPARATIVA DOS ANOS 2003 E 2014
}

\author{
Pedro Augusto Breda Fontão ${ }^{(a)}$, João Afonso Zavattini ${ }^{(b)}$
}

(a) Doutorando pelo Programa de Pós-Graduação em Geografia do Instituto de Geociências e Ciências Exatas, Universidade Estadual Paulista - IGCE/UNESP, pedroabf@ rc.unesp.br.

(b) Professor Adjunto do Departamento de Geografia do Instituto de Geociências e Ciências Exatas, Universidade Estadual Paulista - IGCE/UNESP, zavattini@rc.unesp.br.

\section{Eixo: 3 Climatologia em Diferentes Níveis Escalares: Mudanças e Variabilidades}

\begin{abstract}
Resumo/
Trata-se de um estudo voltado à compreensão de longos períodos de estiagem e/ou pouca precipitação na Região Metropolitana de São Paulo (RMSP), visando através do conhecimento da dinâmica atmosférica na região contribuir para um melhor planejamento e gestão dos recursos hídricos. Para tanto, utilizou-se da análise rítmica dos tipos de tempo nos anos padrão secos de 2003 e 2014, de forma a identificar e comparar através do ritmo dos sistemas atmosféricos as diferentes sequências rítmicas que resultaram em baixa precipitação durante o período. Tais resultados foram discutidos e comparados a outros estudos relevantes realizados na área.
\end{abstract}

Palavras chave: Análise rítmica, precipitação, Climatologia Geográfica.

\section{Introdução}

A variabilidade e irregularidade dos elementos climáticos tem continuamente despertado o interesse do ser humano ao longo do tempo, em particular devido à sua capacidade de influenciar e impactar o ambiente em que vive, através de episódios de caráter excepcional advindos da dinâmica atmosférica. Nesse contexto, a circulação atmosférica apresenta um papel fundamental por desencadear a gênese dos fenômenos, como é o caso da precipitação, mediante um ritmo próprio.

No Brasil, a palavra ‘ritmo’ possui uma relevância histórica em estudos vinculados à Geografia Física, e em particular remetem à interpretação de ritmo climático presente na já consagrada escola brasileira de "Climatologia Geográfica" (MONTEIRO, 2015, p. 5). Tendo por base o "ritmo como a essência geográfica do clima" (MONTEIRO, 1991, p. 131), nas últimas décadas diversos autores têm buscado a compreensão da dinâmica, frequência e encadeiamento dos sistemas atmosféricos para aplicá-la às variáveis ambientais e sociais.

Segundo Monteiro (1991, p. 131), a ideia fundamental que norteia tal paradigma é "exatamente aquela de poder sintonizá-lo às demais dinâmicas das outras esferas: dos processos hidrológicos, geomorfológicos, 
biológicos e (por que não?) os antrópicos”. Além da compreensão do habitual, espera-se identificar e analisar o oposto, ou seja, as arritmias observadas que podem desencadear episódios extremos em que a sociedade não está necessariamente preparada para enfrentar.

Recentemente, em específico durante o período de 2013 a 2015, um assunto intimamente relacionado ao dinamismo atmosférico destacou-se e ganhou repercussão nos meios de comunicação nacionais, através do ritmo pluvial excepcional. Não se tratam de situações de vulnerabilidade às chuvas intensas, ou episódios de cheias e/ou inundações que tem ganhado destaque por, infelizmente, desencadear impactos intensos e tragédias no centro-sul brasileiro. Trata-se, entretanto, da escassez de recursos hídricos desencadeada por um longo período de baixa precipitação no sudeste brasileiro, e de maneira específica, no estado e São Paulo, episódio que ficou conhecido como a Crise Hídrica (COELHO et. al., 2015; MARENGO e ALVES, 2016).

Diversas são as causas apontadas para esta crise. Associados à falta de chuvas há fatores como a demanda crescente pelo uso da água; a vontade política (ou falta de) para o desenvolvimento de obras de infraestrutura e saneamento; degradação ambiental dos mananciais; desperdício do próprio Sistema; expansão urbana desordenada e a falta de um real envolvimento e conhecimento por parte da população (POSTALI, 2016; CESAR NETO, 2016). Tais condições efetivamente contribuíram para o agravamento da crise, e devem ser considerados em análises gerais e/ou detalhadas a respeito da crise.

Entretanto, é inegável o fato que houve baixa precipitação em relação ao habitual da região ao longo do período, numa quantidade e intensidade que os setores públicos e privados não estavam preparados e/ou esperando. Em especial, na Região Metropolitana de São Paulo (RMSP) houve grande repercusão devido à possibilidade de esgotamento de seus sistemas de abastecimento urbano, dentre eles o Sistema Cantareira, manancial mais importante para esta finalidade e responsável por produzir recurso suficiente para abastecer um número próximo da metade de toda a população da RMSP (SABESP, 2016).

A respeito do Sistema Cantareira, deve-se considerar que desde 2004 há um alerta sobre a insuficiência deste sistema, sobretudo no Artigo 16 da renovação de sua outorga, que recomenda à Sabesp "estudos e projetos que viabilizem a redução de sua dependência do Sistema Cantareira" (DAEE, 2004, p.5). Partindo do relatório, é possível verificar que no final de 2003 o sistema estava à beira do colapso, ameaçando uma crise de abastecimento, que felizmente não ocorreu devido à elevada precipitação no verão de 2004. Todavia, fica uma questão não resolvida, pois se tal excepcionalidade já ocorreu uma vez, "por que não adotar medidas de planejamento para evitar uma futura?".

Nesse sentido, o presente artigo tem por objetivo, a princípio, verificar o ritmo pluvial dos anos de 2003 e 2014, habitualmente mais secos, tornando possível através da compreensão da dinâmica das massas de ar 
identificar a participação dos sistemas atmosféricos e a contribuição para a gênese das chuvas no período.

Posteriormente, partindo dos resultados gerados, discutir os tipos de tempo habituais e excepcionais na região e, através da comparação a outros estudos já realizados na área, contribuir para o planejamento e gestão do abastecimento hídrico urbano na área.

\section{Materiais e Métodos}

A Região Metropolitana de São Paulo destaca-se por ser o maior e mais populoso aglomerado urbano do Brasil, e encontra-se inserida na porção leste do estado de São Paulo, quase em sua totalidade no interior da bacia do Alto Tietê. A Figura 1 ilustra a respectiva localização geográfica da RMSP e da região hidrográfica que compõe o Sistema Cantareira, principal sistema de abastecimento urbano, e que fornece a maior parte de seus recursos através das bacias dos rios Piracicaba, Capivari e Jundiaí.

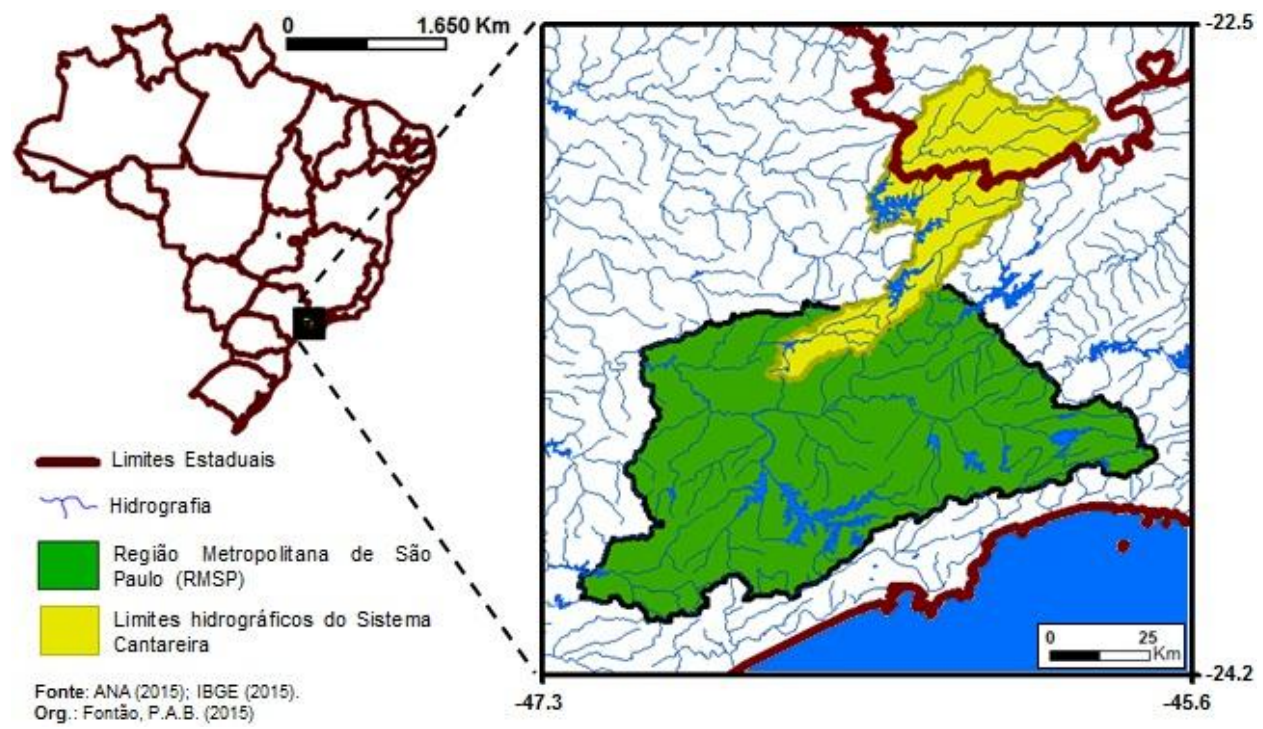

Figura 1 - A Região Metropolitana de São Paulo e o Sistema Cantareira.

Em um estudo realizado anteriormente, Fontão e Zavattini (2016) aplicaram o método da fórmula de Sturges (SILVA, 1980) para a identificação de anos padrão (MONTEIRO, 1973; 2015) na Região Metropolitana de São Paulo e no Sistema Cantareira (localizado ao norte da metrópole), visando observar anos representativos de situações extremas em ambas as localidades. Tendo como base a série histórica compreendida entre 1985 a 2014, foi possível constatar que os anos 2003 e 2014 de fato apresentaram 
uma menor precipitação em relação ao restante do período, conforme se pode observar a síntese dos resultados na Figura 2.

\begin{tabular}{|c|c|c|c|c|c|c|c|c|c|c|c|c|c|c|c|c|c|c|c|c|c|c|c|c|c|c|c|c|c|c|c|}
\hline \multicolumn{32}{|c|}{ Classificação dos anos padrão para a Região Metropolitana de São Paulo } \\
\hline Ano & 85 & 86 & 87 & 88 & 89 & 90 & 91 & 92 & 93 & 94 & 95 & 96 & 97 & 98 & 99 & 00 & 01 & 02 & 03 & 04 & 05 & 06 & 07 & 08 & 09 & 10 & 11 & 12 & 13 & 14 & Total \\
\hline Seco & $\mathbf{X}$ & & & & & & & & & & & & & & & & & & $\mathbf{X}$ & & & & & & & & & & & $\mathbf{X}$ & 3 \\
\hline Tend. a Seco & & & & & & & & & & $x$ & & & & & $\mathbf{X}$ & & & $\mathbf{X}$ & & & & & & & & & & & & & 3 \\
\hline Habitual & & & & & $\mathrm{X}$ & $x$ & & $\mathbf{x}$ & $\mathrm{X}$ & & & & $\mathbf{x}$ & $\mathrm{X}$ & & $\mathbf{x}$ & $\mathbf{x}$ & & & $\mathrm{x}$ & $\mathrm{x}$ & $\mathrm{x}$ & $\mathrm{x}$ & $x$ & & & $\mathrm{X}$ & & $\mathrm{x}$ & & 15 \\
\hline Tend. a Chuv. & & $\mathbf{x}$ & $\mathbf{x}$ & $x$ & & & & & & & $\mathbf{x}$ & & & & & & & & & & & & & & & $\mathbf{x}$ & & $\mathbf{x}$ & & & 6 \\
\hline Chuvoso & & & & & & & $\mathrm{x}$ & & & & & $X$ & & & & & & & & & & & & & $\mathrm{X}$ & & & & & & 3 \\
\hline
\end{tabular}

Classificação dos anos padrão para o Sistema Cantareira

\begin{tabular}{|c|c|c|c|c|c|c|c|c|c|c|c|c|c|c|c|c|c|c|c|c|c|c|c|c|c|c|c|c|c|c|c|}
\hline \multicolumn{32}{|c|}{ Classificação dos anos padrão para o Sistema Cantareira } \\
\hline Ano & 85 & 86 & 87 & 88 & 89 & 90 & 91 & 92 & 93 & 94 & 95 & 96 & 97 & 98 & 99 & 00 & 01 & 02 & 03 & 04 & 05 & 06 & 07 & 08 & 09 & 10 & 11 & 12 & 13 & 14 & Total \\
\hline Seco & & & & & & & & & & & & & & & & & & & $\mathbf{X}$ & & & & & & & & & & & $\mathbf{X}$ & 2 \\
\hline Tend. a Seco & $\mathbf{X}$ & & & & & $x$ & & & & & & & & & & & & $\mathrm{X}$ & & & & & & & & & & & $\mathbf{X}$ & & 4 \\
\hline Habitual & & & $x$ & & $x$ & & & $X$ & $x$ & $x$ & & & $\mathbf{x}$ & $x$ & $\mathbf{x}$ & $\mathbf{x}$ & $x$ & & & $\mathrm{X}$ & $x$ & $x$ & $x$ & & & $\mathrm{X}$ & & 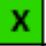 & & & 16 \\
\hline Tend. a Chuv. & & $X$ & & & & & $x$ & & & & & & & & & & & & & & & & & $\mathbf{x}$ & & & $\mathbf{X}$ & & & & 4 \\
\hline Chuvoso & & & & $x$ & & & & & & & $x$ & $x$ & & & & & & & & & & & & & $\mathbf{x}$ & & & & & & 4 \\
\hline
\end{tabular}

Figura 2 - Síntese proposta dos anos padrão para a RMSP e o Sistema Cantareira, no período 1985-2014.

Fonte: FONTÃO e ZAVATTINI, 2016.

Partindo dos anos padrão secos 2003 e 2014, a pesquisa prosseguiu através da coleta de dados em nível diário fornecido pela Estação Meteorológica do Instituto de Astronomia, Geofísica e Ciência Atmosférica da USP (IAG-USP), localizada na cidade de São Paulo - SP. Além dos dados meteorológicos de diversas variáveis (precipitação, temperatura, pressão atmosférica, insolação, umidade relativa, vento e nebulosidade), foram adquiridas cartas sinóticas de superfície em no mínimo dois períodos diários fornecidas pela Marinha do Brasil e imagens de satélite fornecidas pelo Centro de Previsão de Tempo e Estudos Climáticos - CPTEC/INPE e National Climatic Data Center da National Oceanic and Atmospheric Administration (NOAA) em diversos horários, quando disponíveis e/ou existentes. Ainda, foram coletados dados do volume de reservatórios fornecidos pela Companhia de Saneamento Básico do Estado de São Paulo (SABESP) em nível diário e mensal.

A identificação dos sistemas atmosféricos em dois horários diários, 9h e 21h (Horário de Brasília), se deu através da análise rítmica (MONTEIRO, 1971; 2015), procedimento que analisou a variação de ambos os elementos climáticos, através da confecção de gráficos, concomitantemente ao dinamismo sinótico. Para não entrar na questão dos méritos acadêmicos, este estudo optou por utilizar a base proposta pelo autor e a nomenclatura proposta por Zavattini e Boin (2013), por detalhar o avanço dos sistemas frontais, fator 
importante para auxiliar na compreensão do ritmo climático. Pela própria natureza regional da análise rítmica, no momento focaram-se nos dados da estação meteorológica para a identificação dos sistemas atmosféricos, procurando ressaltar a partir disso a importância dos tipos de tempo (DOUGUEDROIT, 2004; VIGNEAU, 2004) para as análises geográficas.

De maneira complementar à realização da análise rítmica, buscou-se identificar o encadeiamento dos sistemas atmosféricos que foram geradores (ou não) de longos períodos de estiagem, e a partir deles, compreender tal dinâmica e contribuir para o planejamento e prevenção de possíveis ocorrências futuras. Alguns estudos já realizados na área contribuíram para o conhecimento do dinamismo da mesma, a citar as obras de Monteiro (1973), Alves Filho (1996), Tarifa (2001), Armani e Galvani (2011) e Ogashawara et. al. (2014).

\section{Resultados e Discussão}

O procedimento metodológico foi aplicado através da utilização de gráficos de análise rítmica e da observação das cartas sinóticas e imagens de satélite. Tal procedimento tornou possível a identificação diária/horária das massas de ar e sistemas perturbadores que atuaram ao longo da RMSP, em sucessão. A Figura 3 permite visualizar a síntese dos resultados, e respectiva precipitação ocorrida no primeiro semestre dos anos 2003 e 2014.

No primeiro trimestre, correspondente ao verão, pode-se notar uma maior atividade frontal (e suas variações) no ano de 2003 em relação ao ano de 2014, dinamismo que acabou resultando em precipitações mais elevadas e bem distribuídas entre os meses de janeiro e primeiros vinte dias de fevereiro. A participação de massas de ar estáveis durante 27 dias seguidos no ano de 2014, entre janeiro e fevereiro, acabou comprometendo um período habitualmente chuvoso, gerando um possível bloqueio atmosférico contra a atuação de sistemas perturbadores de sul neste setor do estado de São Paulo. Já no ano de 2003, a atuação da Frente Estacionária resultou em precipitação superior a 100 milímetros entre os dias 27 e 28 de janeiro, além de sucessivas perturbações originadas pelo avanço de frentes e pelas linhas de instabilidade tropicais.

O mês de março apresentou poucos volumes acumulados de precipitação em 2003, resultados de chuva convectiva passageira ou das rápidas passagens frontais que estabilizaram o tempo na segunda quinzena. Já para o ano de 2014, o mesmo mês mostrou-se mais próximo do padrão esperado, com chuvas bem 
XVII Simpósio Brasileiro de Geografia Física Aplicada

I Congresso Nacional de Geografia Física
OS DESAFIOS DA GEOGRAFIA FÍSICA NA FRONTEIRA DO CONHECIMENTO

Instituto de Geociências - Unicamp

Campinas - SP

28 de Junho à 02 de Julho de 2017

distribuídas e temperaturas elevadas, resultado de uma maior atuação dos mecanismos frontológicos promotores de chuvas na região, voltando a estabilizar-se no final do mês sob o efeito de massas polares e polar velha.
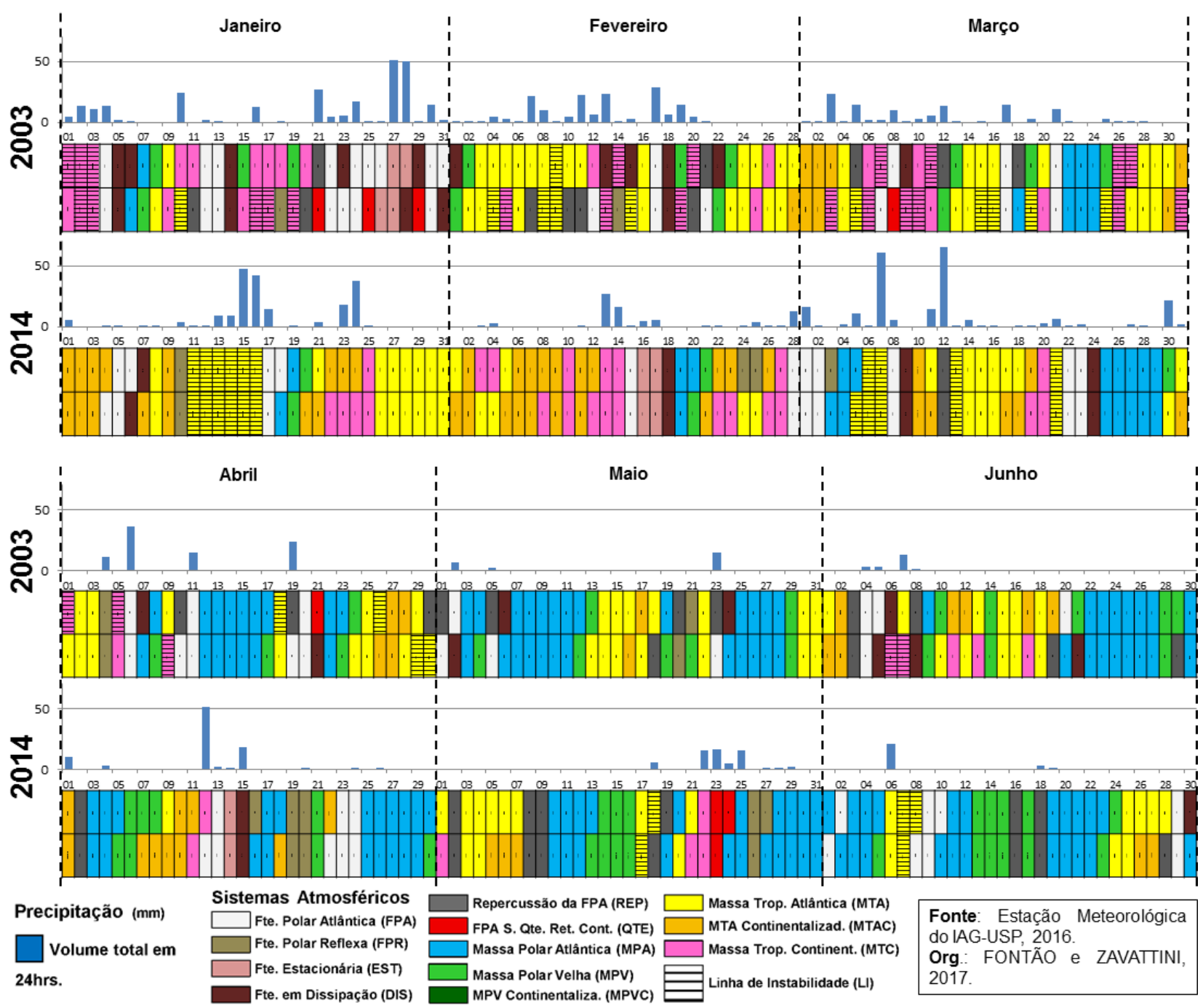

Figura 3 - Análise Rítmica de São Paulo para o primeiro semestre de 2003 e 2014.

Já o segundo trimestre, correspondente ao outono, coincidiu com temperaturas amenas advindas do anticiclone migratório polar (MPA e MPV) e poucas precipitações. Todavia a baixa quantidade de chuva não pode ser considerada algo excepcional, pois o regime hídrico das precipitações no estado tende a concentrar as chuvas no período de outubro a março (SANT'ANNA NETO, 1995), tocante à primavera e verão. Nesse período, é possível notar o avanço de algumas ondas de frio que resultaram em baixa precipitação e sucessivos dias de atuação da massa polar atlântica (31,3\% do período em 2003 e 34,6\% em 


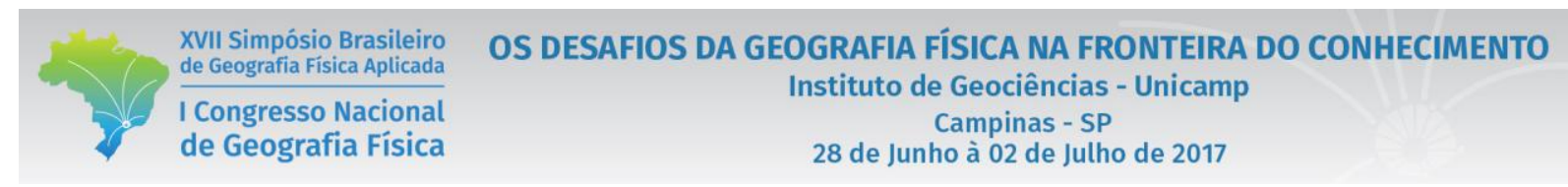

2014). Ainda, o "envelhecimento" da MPA resultou em uma importante participação da Massa Polar Velha (MPV) e da Massa Tropical Atlântica (MTA), responsáveis por tipos de tempo estáveis e pouca ocorrência de chuva.

A Figura 4 ilustra o segundo semestre da síntese da análise rítmica dos anos 2003 e 2014. O terceiro trimestre, correspondente ao inverno, também apresentou um padrão pouco chuvoso em ambos os anos e algumas passagens frontais que provocaram pequenos volumes de precipitação e ondas de frio. No ano de 2014, nota-se entre os dias 7 a 10 de julho e 16 e 21 de setembro que mesmo uma maior atividade de sistemas perturbadores de sul não foi suficiente para provocar grandes volumes de precipitação.

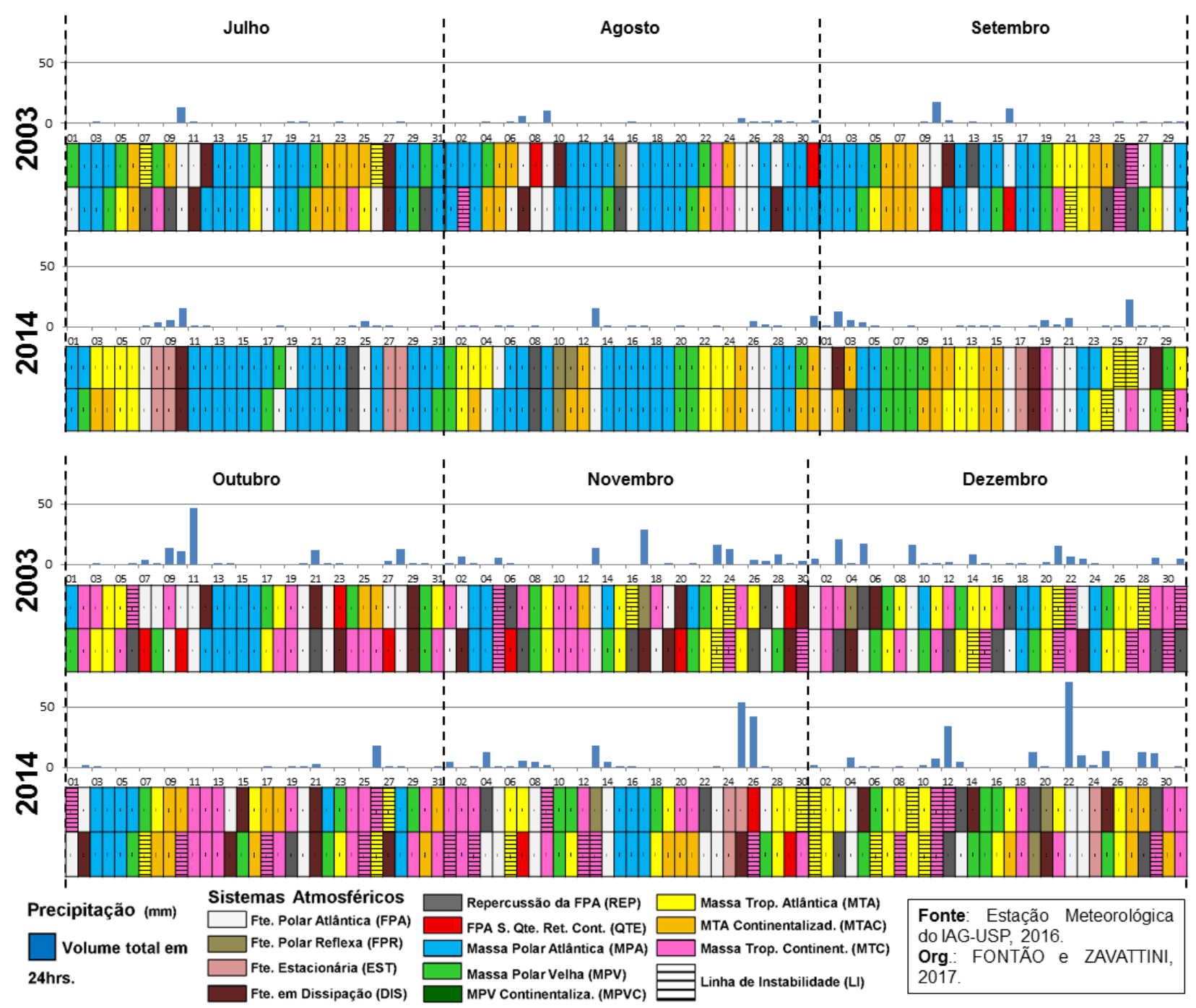

Figura 4 - Análise Rítmica de São Paulo para o segundo semestre de 2003 e 2014. 
Assim como no outono, o inverno contou com uma grande participação da MPA (38\% do total do trimestre em 2003 e 33,7\% em 2014), e exceto nos dias com avanço frontal, predominou na maior parte do período tipos de tempo estáveis com atuação das MPV, MTA e MTAC. Novamente ressalta-se que a pouca precipitação no inverno não é algo excepcional para a região, todavia não deixou de ser um volume baixo de chuva para o total de seis meses (abril a setembro), correspondente a 206,4 milímetros em 2003 e 322 milímetros em 2014.

O quarto trimestre, correspondente à primavera em ambos os anos, mostrou-se pouco chuvosa em relação ao habitual nos dois casos. Destaca-se o ano de 2003, onde não houve nenhum caso de atuação da frente estacionária (EST), e as passagens frontais após a metade de Outubro se mostraram curtas e escassas, resultando em baixos índices de precipitação no período. Da mesma maneira, a forte atuação das massas tropicais contribuiu para tipos de tempo quente e seco, favorecendo a evapotranspiração e prolongando uma possível estiagem em rios e reservatórios.

No ano de 2014, a demora na retomada das chuvas acentuou ainda mais os impactos da crise hídrica para a população da região. Todavia, apesar de ter sido prolongada a estiagem até a segunda metade de novembro, houve importantes passagens frontais nos períodos 25-26 de novembro (EST) e em dois períodos do mês de dezembro que contribuíram para atenuar um pouco os eventuais problemas em reservatórios.

Em síntese, o ano de 2003 apresentou uma pluviosidade próxima do habitual no início do ano (janeiro e fevereiro), e uma participação próxima de 1/3 do período total de sistemas frontais no primeiro trimestre. A partir de março e ao longo do ano, as precipitações nesse ano permaneceram reduzidas, permitindo uma forte atuação de massas de ar estáveis, inclusive ao longo da primavera, período que se mostrou pouco chuvoso e de baixa atuação de sistemas frontais.

O ano de 2014, de maneira sintética, mostrou-se pouco chuvoso no início do ano, com forte participação de massas tropicais estáveis gerando tipos de tempo quente e seco. Ao longo do ano, a baixa participação de sistemas frontais se manteve, resultando em maiores volumes de precipitação somente no final do mês de novembro e dezembro. Tal fator contribuiu para um predomínio de tipos de tempo estáveis, resultando em uma participação elevada de massas de ar ao longo do ano.

A partir dos dados obtidos nesse artigo, a próxima etapa da pesquisa será aplicar tais resultados na compreensão mais detalhada da gênese das chuvas. E, após essa etapa, verificar as eventuais consequências nos sistemas de abastecimento urbano, e respectivos volume, vazão natural, vazão de retirada e impactos na população residente. Antecipando as etapas sugeridas, a Figura 5 torna em 
XVII Simpósio Brasileiro de Geografia Fisica Aplicada

I Congresso Nacional de Geografia Física
OS DESAFIOS DA GEOGRAFIA FÍSICA NA FRONTEIRA DO CONHECIMENTO

Instituto de Geociências - Unicamp

Campinas - SP

28 de Junho à 02 de Julho de 2017

evidência o volume total do Sistema Cantareira, gráfico básico para um estudo mais detalhado que envolva outras variáveis geográficas e os outros reservatórios/mananciais da RMSP. (SABESP, 2016).

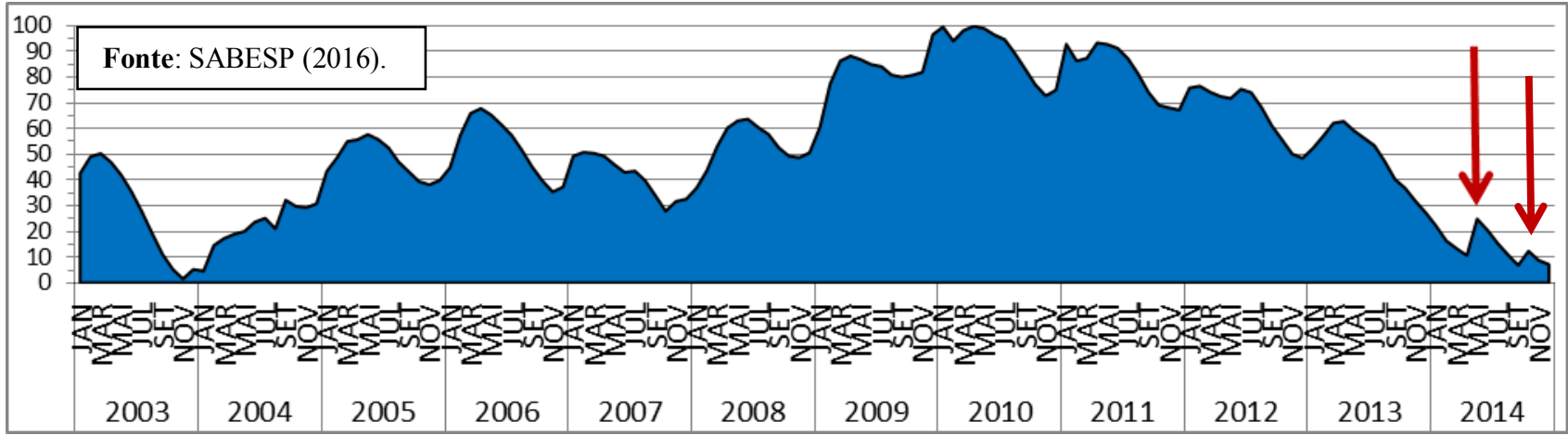

Figura 5 - Variações do volume de água armazenado no Sistema Cantareira (2003-2014), em porcentagem total.

Na figura, é possível verificar como estava o nível do reservatório em novembro de 2003, após a forte estiagem que ocorreu nesse ano. Ainda, em destaque (setas vermelhas), encontra-se a inclusão de dois volumes 'artificiais' (volume morto), tornando em evidência a crise hídrica que atingiu o reservatório em 2014, e provocou sérios problemas de abastecimento hídrico à população na Região Metropolitana de São Paulo (RMSP).

\section{Considerações Finais}

Os procedimentos metodológicos aplicados permitiram evienciar a dinâmica do tempo atmosférico em nível regional para os dois anos secos, apresentando um padrão com pouca atuação de sistemas frontais em relação a outros estudos já realizados na área com metodologia semelhante. A sucessão dos estados atmosféricos na Região Metropolitana de São Paulo apresentou pouca variabilidade entre os dois períodos anuais e prolongamento do período de estiagem, assim como uma baixa participação de sistemas provocadores de chuva nos meses habitualmente mais chuvosos, em especial no verão de 2014. Os meses de outono e inverno mostratam-se mais próximos do habitual, todavia corresponde ao período pouco chuvoso típico do regime hídrico do clima tropical. 
Nesse sentido, verifica-se nesse estudo a constatação de que "as passagens da Frente Polar Atlântica (FPA), que acontecem o ano inteiro sobre a metrópole paulistana, são as principais responsáveis pela regularidade das chuvas, mesmo no verão" (ZAVATTINI, 2014). Todavia, Ribeiro (2000) atenta para observar na análise rítmica a distribuição da quantitade e dos volumes de chuva, ressaltando que "o 'ano seco' tem um significado para os propósitos da agricultura que não será, necessariamente, o mesmo para o sistema de geração hidrelétrica, pois o que está em jogo não são os totais quantitativos de chuvas, mas sim a sua distribuição temporal". O prolongamento das estiagens, por exemplo, mostrou-se um ponto interessante a se destacar a partir desse argumento.

No estudo, foi possível verificar que a pouca precipitação frontal no início do ano, associada à fraca retomada das chuvas nos meses de outubro e novembro, acabou contribuindo para a crise hídrica de 2014, que já havia sido iniciada na primavera de 2013. É importante ressaltar que tal padrão seco, apesar de pouco recorrente, é algo inerente ao dinamismo atmosférico e pode voltar a ocorrer ao longo das próximas décadas, carecendo de um planejamento e gestão por parte dos órgãos públicos e privados voltados ao abastecimento hídrico da metrópole e do estado de São Paulo.

Para finalizar, conserva-se como reflexão uma citação de Monteiro (p.11), publicada no ano de 1971, e que apesar de abordar a área metropolitana de São Paulo na década de 1970, aparenta uma problemática de caráter atemporal:

"O abastecimento urbano em água conduz a um equacionamento racional do aprovisionamento.

Se o volume dos reservatórios tornava-se insuficiente ao volume populacional e sobretudo, se o ritmo climático atual agia de modo a colocar em carência um produto vital, todo um novo sistema de abastecimento teve que ser planejado e construido para assegurar as disponibilidades da região metropolitana (...) Um 'ano sêco', assim tomado por um simples critério de inferioridade em relação aos índices normais poderá ou não implicar na ocorrência e diferentes 'estados de sêca' considerados como períodos em que a ocorrência de chuva foi insuficiente a prover as determinadas e diferentes necessidades".

\section{Agradecimentos}


Esta pesquisa encontra-se em desenvolvimento por meio de apoio da Coordenação de Aperfeiçoamento de

Pessoal de Níveis Superior - CAPES, através do financiamento de bolsa de doutorado desde Abril de 2015. O apoio da referida instituição torna possível o desenvolvimento e a continuidade desse estudo.

\section{Bibliografia}

ALVES FILHO, A. P. Episódios pluviais intensos na Região Metropolitana de São Paulo: uma avaliação no decênio 1982-1991. 1996. 197 f. Dissertação (Mestrado em Ciências) - Faculdade de Filosofia, Letras e Ciências Humanas, Universidade de São Paulo, São Paulo.

ARMANI, G.; GALVANI, E. Fluxos polares e o ritmo dos sistemas atmosféricos no nordeste do estado de São Paulo. Sociedade \& Natureza, Uberlândia, v. 23, n. 1, p. 7-22, 2011.

CESAR NETO, J. C. Crise hídrica no estado de São Paulo. Geousp - Espaço e Tempo (Online), v. 19, n. 3, p. 479484, 2016

COELHO, C. A. S.; CARDOSO, D. H. F.; FIRPO, M. A. F. Precipitation diagnostics of an exceptionally dry event in São Paulo, Brazil. Theoretical and Applied Climatology. v. 125, p. 1-16, 2015. Disponível em: <http://link.springer.com/article/10.1007\%2Fs00704-015-1540-9>. Acesso em: 04 nov. 2015.

DAEE. Portaria DAEE N. 1213, de 06 de Agosto de 2004. São Paulo: Departamento de Água e Energia Elétrica do Estado de São Paulo, 2004.

DOUGUEDROIT, A. Quelle "exception française" en matière de "types de temps" ?. Norois, n. 191, p. 33-39, 2004.

FONTÃO, P. A. B.; ZAVATTINI, J. A. Análise Temporal, Espacial e Identificação do padrão das chuvas na Região Metropolitana de São Paulo e no Sistema Cantareira. In: XIII Congresso Nacional de Meio Ambiente de Poços de Caldas, 8., 2016, Poços de Caldas, MG. Anais Congresso Nacional de Meio Ambiente de Poços de Caldas. Poços de Caldas, MG: GSC Eventos, 2016. p. 1-8.

MARENGO, J. A.; ALVES, L. M. Crise hídrica em São Paulo em 2014: seca e desmatamento. Geousp - Espaço e Tempo (Online), v. 19, n. 3, p. 485-494, 2016.

MONTEIRO, C. A. F. A análise rítmica em climatologia: problemas da atualidade climática em São Paulo e achegas para um programa de trabalho. Climatologia. v. 1, n. 1, p. 1-21, 1971.

MONTEIRO, C. A. F. A Dinâmica Climática e as Chuvas no Estado de São Paulo: estudo geográfico sob a forma de atlas. São Paulo, SP: USP/IG, 1973.

MONTEIRO, C. A. F. Clima e excepcionalismo: conjecturas sobre o desempenho da atmosfera como fenômeno geográfico. Florianópolis, SC: Editora UFSC, 1991.

MONTEIRO, C. A. F. (Org.). A construção da Climatologia Geográfica no Brasil. Campinas, SP: Editora Alínea, 2015.

OGASHAWARA, I.; ZAVATTINI, J. A.; TUNDISI, J. G. The climatic rhythm and blooms of cyanobacteria in a tropical reservoir in São Paulo, Brazil. Brazilian Journal of Biology (Impresso), v. 74, p. 72-78, 2014.

POSTALI, A. Falta de chuvas não é única razão da crise do Cantareira. São Paulo, SP: Agência USP de notícias, 2015. Disponível em: <http://www.usp.br/agen/?p=199820>. Acesso em: 26 jan. 2016.

RIBEIRO, A. G. A climatologia dinâmica na perspectiva da análise rítmica. Sociedade \& Natureza, Uberlândia, v. 12, n. 24, p. 47-62, jul./dez. 2000.

SABESP. Companhia de Saneamento Básico do Estado de São Paulo. Disponível em: <http://site.sabesp.com.br/>. Acesso em: 10 out. 2016. 
SANT'ANNA NETO, J. L. As Chuvas no estado de São Paulo: contribuição ao estudo da variabilidade e tendência da pluviosidade na perspectiva da análise geográfica. 1995. 252 f. Tese (Doutorado em Ciências). Faculdade de Filosofia, Letras e Ciências Humanas, Universidade de São Paulo, São Paulo.

SILVA, B. N. A propósito de uma técnica de seleção de intervalos de classe para fins de mapeamento. Geografia, v. 5, n. 9-10, p. 85-96, 1980.

TARIFA, J. R. O ritmo e a prática do estudo dos climas de São Paulo (1970-2000). In: TARIFA, J. R.; AZEVEDO, T. R. (Org.). Os climas na cidade de São Paulo: teoria e prática. São Paulo, SP: Universidade de São Paulo, 2001. p. 11-33.

VIGNEAU, J. P. Un siècle de "type de temps": epistémologie d'un concept ambigu. Norois, n. 191, p. 11-13, 2004.

ZAVATTINI, J. A.; BOIN, M. N. Climatologia Geográfica: teoria e prática. Campinas, SP: Editora Alínea, 2013.

ZAVATTINI, J. A. O uso das cartas sinóticas nos estudos de climatologia geográfica. In: SILVA, C. A.; FIALHO, E. S.; STEINKE, E. T. (Org.). Experimentos em Climatologia Geográfica. Dourados, MS: UFGD, 2014. p. 243269. 